\title{
DOAÇÃO DE ORGÃOS PARA TRANSPLANTES: INFORMAÇÃO E OPINIÃO DE MORADORES DO INTERIOR DO ESTADO DE SÃO PAULO
}

\author{
Organ donation for transplants: knowledge and beliefs of residents \\ from a country region of the Sao Paulo State
}

Jeovane G Faria ${ }^{1}$, Leda Maria Branco ${ }^{2}$, Priscila Silveira Duarte ${ }^{4}$,
Maria Cristina Oliveira Santos Miyazaki ${ }^{2}$, Mário Abbud-Filho ${ }^{3}$

\section{RESUMO}

A escassez de órgãos para transplante está relacionada a múltiplos fatores, inclusive a percepção da população sobre o tema. Objetivo: informar e identificar a opinião sobre doação de órgãos e transplante em moradores de uma cidade do interior do estado de São Paulo. Métodos: durante a Semana Nacional de Doação de Órgãos e Tecidos, indivíduos adultos foram solicitados a responder um questionário contendo perguntas sobre doação e transplante de órgãos. Resultados: Participaram 303 adultos (52\% mulheres), 36\% com nível de ensino superior. Quase todos entrevistados (99\%) haviam ouvido falar sobre doação e transplantes. Embora 92\% dos participantes tenham demonstrado atitude positiva em relação à doação, apenas $65 \%$ haviam informado à família sobre o desejo de doar. A maioria (90\%) concordou com a retirada de órgãos de pacientes em morte cerebral, mas esse percentual diminuiu quando o paciente era membro da família (86\%). Indenização para doadores vivos (90\%) e comércio de órgãos (79\%) foram rejeitados pelos entrevistados e $95 \%$ dos participantes disseram que os transplantes intervivos aparentados deveriam ser incentivados. A idade não foi considerada critério adequado de distribuição; $60 \%$ opinaram que crianças deveriam ter prioridade para transplantes e $75 \%$ que idosos ( $<65$ anos) têm direito ao transplante. A maioria concordou com a inclusão de subgrupos populacionais como receptores, desde que os critérios de alocação de órgãos fossem respeitados: estrangeiros (73\%), fumantes (89\%), obesos (96\%), prisioneiros e usuários de drogas (88\%). Conclusão: Nossos resultados confirmaram a presença de conhecimento e compreensão adequada sobre doação de órgãos e transplantes, bem como ausência de atitudes discriminatórias na população estudada. Comparação com análise anterior realizada na mesma cidade detectou melhora dos itens avaliados em relação à doação e transplante de órgãos.

Palavras chave: Transplante, Conhecimento, Doação de órgãos.

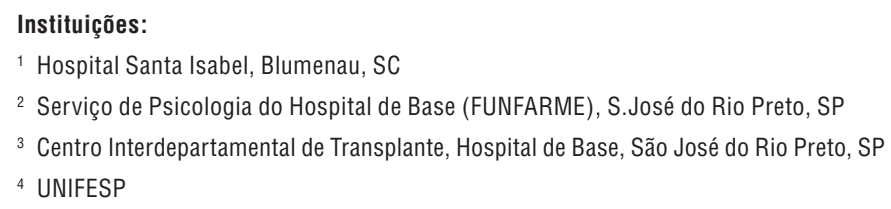

Correspondência:

Leda Maria Branco

Av. Brigadeiro Faria Lima, 5416

CEP 15090-000 - São José do Rio Preto - SP, Brasil

Fone/Fax: 17 3201-5704

E-mail: ledambranco@hotmail.com

Recebido em: 02.07.2007

Aceito em: 01.08.2007

\section{INTRODUÇÃO}

Nos últimos anos houve um aumento significativo na divulgação de informações e no número de doações de órgãos (DO), embora a demanda por transplantes ainda supere de forma significativa a oferta ou disponibilidade de órgãos no Brasil e no mundo ${ }^{1-3}$. Organizar políticas públicas de doação, conscientização e distribuição de órgãos é um desafio tanto para os órgãos federais de saúde quanto para as instituições e profissionais envolvidos no processo doação-transplante. As dificuldades enfrentadas para aumentar o número de doadores envolvem questões como religiosidade, nível educacional da população, mitos em relação aos transplantes, diagnóstico de morte cerebral e critérios utilizados para distribuição de órgãos. ${ }^{4-8}$

A distribuição é provavelmente um dos temas mais polêmicos e debatidos em relação aos transplantes de órgãos e tecidos. Questões sobre prioridade para crianças em relação a adultos, tempo em lista de espera, escolha do receptor baseada na histocompatibilidade surgem com maior freqüência na medida em que a população se torna mais bem informada. Existem dúvidas em relação a muitas 
questões relacionadas ao transplante e doação de órgãos, inclusive, entre os profissionais que atuam na área. ${ }^{2,9}$ Assim, profissionais e estudantes das áreas jurídica e de saúde, bem como a população em geral, devem ser constantemente consultados quanto a questões éticas e morais relacionadas aos programas de doação e transplante de órgãos e tecidos. .,5,-10 $^{1}$

Uma discussão sobre a escassez de órgãos deve envolver assuntos que permitam detectar a percepção pública sobre o tema, incluindo o nível de conhecimento e atitudes dos profissionais da saúde sobre o processo de identificação do doador e do consentimento da família para doar, bem como questões etnoculturais que devem ser constantemente reavaliadas. ${ }^{4,5-10}$

Modificar a opinião pública em relação à doação de órgãos por meio de campanhas é uma tarefa que exige abordar mitos sobre retirada de órgãos, morte encefálica, roubo e tráfico de órgãos, questões que requerem informação adequada e educação precoce e continuada. ${ }^{11-13}$

\section{OBJETIVO}

O objetivo deste estudo foi informar e identificar a opinião da população em relação à doação de órgãos e transplante em moradores de uma cidade de médio porte do interior do estado de São Paulo.

\section{MÉTODOS}

O estudo descritivo foi realizado ao longo de um dia em dois pontos de grande freqüência popular na cidade de São José do Rio Preto, São Paulo, Brasil, durante a Semana Nacional de Doação de Órgãos e Tecidos. O grupo de entrevistadores foi constituído de profissionais da saúde e estudantes de Psicologia, Enfermagem e Serviço Social. Os participantes foram convidados a responder a um questionário, quando passavam pelos pontos da campanha.

Para os que concordaram, foram fornecidas explicações sobre o estudo e, após consentimento livre e esclarecido, foi apresentado um questionário contendo 30 itens relacionados à opinião e conhecimento sobre doação e transplante de órgãos e tecidos, critérios de distribuição de órgãos, morte cerebral e atitudes discriminativas frente a subgrupos da população (fumantes, idosos, obesos, prisioneiros, etc). Após responderem ao questionário, os colaboradores receberam informações sobre a situação do processo de doação e transplante de órgãos no país, bem como as devidas orientações. Os que não responderam ao questionário receberam as mesmas informações.

\section{RESULTADOS}

Participaram do estudo 303 pessoas, 157 (51,81\%) mulheres e 146 (48,19\%) homens, 56,44\% na faixa etária entre 20 e 40 anos, 63,69\% com pelo menos a primeira série do Ensino Médio e 36\% com nível superior de escolaridade.

A maioria dos participantes afirmou ter ouvido falar sobre transplante de órgãos (99\%), sabia da existência do programa de captação de órgãos e tecidos para transplante $(85,5 \%)$ e estava ciente de que são realizados transplantes no Brasil (99\%). Grande parte dos entrevistados $(76,24 \%)$ relatou saber a respeito do programa de captação em São José do Rio Preto e que transplantes eram feitos nesta cidade $(90,43 \%)$.
Em relação ao estudo realizado anteriormente, ${ }^{2}$ houve um aumento na atitude positiva quanto à doação de órgãos e tecidos, que subiu de $78 \%$ para $92 \%$. O ato de informar a família sobre o desejo de doar os órgãos, entretanto, pouco variou: $65 \%$ no estudo atual e $61 \%$ no estudo anterior. ${ }^{2}$ Em relação ao fato de pacientes em morte encefálica serem considerados doadores potenciais, $80 \%$ dos participantes relataram estar cientes da informação e $90 \%$ concordaram com a retirada de órgãos de pacientes diagnosticados. Entretanto, esse percentual diminuiu para $86 \%$, caso o potencial doador possuísse algum parentesco com o entrevistado. Entre os participantes que não concordaram com a retirada dos órgãos em pacientes com morte encefálica (10\%), 56\% justificaram essa postura apontando dúvidas relativas no diagnóstico de morte encefálica como o principal motivo para a negativa em doar órgãos. Uma comparação entre os dados obtidos neste estudo e os dados do estudo anterior ${ }^{2}$ não evidenciou mudanças em relação à questão da morte encefálica, embora tenha havido um aumento na atitude positiva em relação à doação (78\% no estudo anterior ${ }^{2}$ e $92 \%$ no estudo atual).

O profissional responsável por informar a família sobre a morte encefálica do paciente deveria ser o médico para $42 \%$ dos participantes, o psicólogo (25\%) ou o coordenador da Unidade de Transplantes (12\%). Um diagnóstico fornecido em conjunto pela equipe hospitalar foi apontado por $12 \%$. Não houve mudança nesse item, quando os dados os atuais foram comparados com os dados do estudo anterior.

A maioria (90\%) mostrou-se contrária a qualquer tipo de indenização (dinheiro e bens materiais) para doador vivo, seja ele aparentado ou não com o receptor, o que confirma os resultados do estudo anterior. ${ }^{2}$ Quanto ao comércio de órgãos humanos, 78\% dos participantes mostraram-se contrários a este tipo de comportamento (tema abordado sob a perspectiva ética na literatura). ${ }^{6}$ A recompensa não é pagamento em dinheiro, e pode ser uma forma de gratificação oferecida pelo receptor ou pelo governo, para compensar o tempo sem trabalhar, custos da viagem etc. O comércio implica no pagamento em dinheiro pelo órgão doado. No comércio, o órgão é tratado como uma "commoditie", podendo ser vendido ou comprado. Qual a diferença entre recompensa e comércio? Isso foi explicado às pessoas, para que elas pudessem responder? Como foi explicado? Isso foi explicado dessa forma.

Em relação aos critérios de distribuição de órgãos de doador cadáver, $61,72 \%$ não consideraram idade um critério adequado de distribuição, 60,4\% concordaram que crianças devem ter prioridade na lista de espera e 74,59\% acreditavam que idosos (acima de 65 anos) também tinham direito ao transplante. No estudo anterior, ${ }^{2} 66 \%$ não aprovavam a exclusão de idosos e $56 \%$ responderam que crianças devem ter prioridade na lista de espera.

Nos itens referentes a subgrupos populacionais, 73,27\% concordaram que estrangeiros recebam órgãos de brasileiros, desde que os critérios da fila de espera e/ou de compatibilidade sejam respeitados. Ainda, $89 \%$ responderam que não deveriam ser negados órgãos para fumantes, que obesos têm o mesmo direito que o resto da população de receber órgãos (96\%) e que os transplantes poderiam ser oferecidos para prisioneiros e usuários e/ou dependentes de drogas (88\%). O objetivo da pergunta era saber se havia alguma discriminação para a doação. Um fumante, prisioneiro, ou usuário de droga com insuficiência renal crônica pode ou não receber um transplante? Um hepatopata que adoeceu por hepatite adquirida por uso de seringa contaminada não pode receber um transplante de fígado? 
Ser o primeiro da fila de espera é o critério mais justo de distribuição para $65 \%$ e $81 \%$ responderam acreditar que autoridades, como o Papa e os presidentes do Brasil e dos Estados Unidos, deveriam sujeitar-se aos mesmos critérios de distribuição de órgãos que a população em geral. Estes dados são também compatíveis com os dados obtidos anteriormente. ${ }^{2}$

Os transplantes com doadores vivos aparentados devem ser incentivados na opinião de $95 \%$ dos participantes, sendo que esse percentual diminui para $89 \%$, quando se trata de doador vivo não-parente. A ética é definida pelos costumes e hábitos de uma sociedade. A pergunta faz parte do objetivo do trabalho, que visa conhecer se a sociedade aprova ou não o uso de doadores não parentes. Até um ano atrás, a China, aprovava execução de prisioneiros para retirada de órgãos.

\section{DISCUSSÃO}

Quando comparado com estudo anterior ${ }^{2}$ realizado no mesmo centro durante campanha anual prévia (2002) utilizando o mesmo questionário, houve aumento nas porcentagens de informações relativas a questões sobre doação e transplante de órgãos e tecidos. Este aumento reflete-se na ampliação da atitude positiva quanto à doação. ${ }^{2}$

Os dados encontrados neste estudo revelam ainda uma similaridade com os resultados encontrados em pesquisas semelhantes, onde se concluiu que os órgãos devem ser doados sem distinção de raça e/ ou religião, mas com prioridade para as crianças. ${ }^{2,6,10,15}$

\section{CONCLUSÃO}

Os resultados, embora restritos à população de uma região Noroeste do estado de São Paulo, revelam avanços na conscientização sobre
Quadro 1. Principais tópicos comparativos entre estudo anterior ${ }^{2}$ e o estudo atual

\begin{tabular}{lcc}
\hline & Estudo anterior $^{2}$ & Estudo atual \\
\hline Atitude positiva quanto à doação & $78 \%$ & $92 \%$ \\
$\begin{array}{l}\text { Informou família sobre desejo de doar } \\
\begin{array}{l}\text { Concordam com retirada de órgãos em } \\
\text { casos de morte cerebral (doador não }\end{array}\end{array}$ & $61 \%$ & $65 \%$ \\
$\begin{array}{l}\text { parente) } \\
\begin{array}{l}\text { Concordam com a retirada de órgãos em } \\
\text { casos de morte cerebral (doador parente) }\end{array}\end{array}$ & $90 \%$ & $90 \%$ \\
$\begin{array}{l}\text { Dúvidas em relação ao diagnóstico de } \\
\text { morte cerebral }\end{array}$ & $12 \%$ & $86 \%$ \\
\hline
\end{tabular}

a necessidade de doação de órgãos, sugerem necessidade de futuros estudos e a relevância da manutenção freqüente das campanhas pró-doação. Faz-se necessária maior participação dos indivíduos beneficiados pela doação nessas campanhas, visando representar um modelo que, por ter passado pelo processo de avaliação e espera por um órgão e transplante, pode evidenciar mais claramente as percepções associadas ao processo.

Fortalecer as políticas públicas no que tange à legislação e à transparência do processo doação-transplante também é necessário, uma vez que, mesmo com o maior sistema público de transplante do mundo, o Brasil ainda apresenta taxas de doação-transplante com potencial de crescimento bastante significativo, quando comparadas às de outras nações, como a Espanha, onde se tem a maior quantidade de doações por milhão de população do mundo. ${ }^{16}$

\section{ABSTRACT}

Organ shortage for transplantation is due to multiple factors, including people's perception on such issue. Purpose: to inform and identify the opinion on organ donation and transplantation in residents of a country city of the state of Sao Paulo Methods: participants were asked to answer a questionnaire during the National Week of Brazilian Organs and Tissue Donation and Transplantation in a medium size country town. Results: 303 adults (52\% women), 36\% of them with college degree participated in the study. The majority (99\%) had already heard on organ donation and transplantation. Although $92 \%$ of participants had a positive attitude towards organ donation, only $65 \%$ had informed their families about their wish to become a donor. Among those who agreed that organs from patients with cerebral death must be retrieved (90\%), the percentage decreased when the donor was a relative (86\%). 90\% were against any type of reward for living donors and organ selling (79\%). Age was considered a non-appropriate distribution criteria, $60 \%$ believed that children must have priority, and $75 \%$ thought that elder persons ( $<65$ years) are eligible to the transplantation. The majority agreed that subgroups may receive organs, but the criteria to the waiting list must be respected: foreigners (73\%), smokers (89\%), obese (96\%), prisoners and drug users (88\%). 95\% believed that living donor transplantation should be encouraged. Conclusion: results show attitudes of solidarity among the population, as well as an absence of discriminative attitudes towards the subpopulation of receptors. Comparison of data with the one found in a previous study conducted in the same location shows an increase towards a positive attitude concerning organ donation and transplantation.

Keywords: Transplantation, Knowledge, Donation of Organs

\section{REFERÊNCIAS}

1. Associação Brasileira de Transplante de Órgãos (ABTO). www.abto.org.br

2. Duarte OS, Pericoco S, Miyazaki MCOS, Ramalho HJ, Abbud-Filho M. Transplant Proc. 2002;34:458-9.
3. Rumsey S, Hurford DP, Cole AK. Influence of knowledge and religiousness on attitudes toward organ donation. Transplant Proc. 2003;35:2845-50.

4. Molzahn AE, Starzomski R, McCormick J. The supply of organs for transplantation: issues and challenges. Nephrol Nurs J. 2003;30(1):17-26. 
5. Beutel ME, Greif-Higer G, Haselbacher A, Galle PR, Otto G. Attitudes towards cadaveric organ donation - results from a representative survey of the German population. Z Gastroenterol. 2006;44(11):1135-40.

6. Coelho JCU, Cilião C, Parolin MB, Freitas ACT, Filho OPG, Saad DT Pistori RP, Martone D. Opinião e conhecimento da população de cidade de Curitiba sobre doação e transplante de órgãos. Rev. Assoc Med Bras. 2007;53(5):421-5.

7. Schirmer J, Leite RF, Bartira RA, Alessandra SS, Fujinami TI, Lemos MC, Kian FM Doação de orgãos e tecidos: o que sabem os estudantes do ensino médio? Einstein. 2007;5(3):213-9.

8. Rodrigues AM, Sato EH. Conhecimento e atitude da população do Hospital São Paulo sobre doação de córneas. Arq Bra Oftalmol 2002; 65:637-40.

9. Dutra MM, Bonfim TA, Pereira IS, Figueiredo IC, Dutra AM, Lopes AA Knowledge about transplantation and attitudes toward organ donation: a survey among medical students in northeast Brazil. Transplant Proc. 2004 May;36(4):818-20.

10. Passarinho LEV, Gonçalves MP, Garrafa V. Estudo bioético dos transplantes renais com doadores vivos não-parentes no Brasil: a ineficácia da legislação no impedimento do comércio de órgãos. Rev Assoc Med Bras. 1992;49(4):382-4.
11. Traiber C, lopes MHI. Educação para doação de orgãos Scentia Medica 2006:16(4):178-82

12. Alves CEM, Bergamini G, Lagares HB, Souza IA, Vieira LS, Campos RLOR, Martins SRO. Doação de órgãos: a atividade de relações públicas em favor da vida. O caso MG transplantes [Monografia apresentada ao Departamento de Ciência da Comunicação, como pré-requisito para a disciplina de Projetos Experimentais em Relações Públicas II] Belo Horizonte: Centro Universitário de Belo Horizonte. Curso de Comunicação Social-Relações Publicas, 2006

13. Ferraz AS. Doação de órgãos para transplante: considerações legais, éticas e sociais. Revista Virtual de Medicina [serial on line] 1999 jan-mar;1(5). Disponivel em http:// medonline.com.br.

14. Bakdash T, Scheper-Hughes, N. Is it ethical for patients with renal disease to purchase kidneys form the world's poor? PLoS Medicine / Public Library of Science. 2006;3(10):e349.

15. Avila GN, Avila GA, Gauer GJC. Is the unified list system for organ transplants fair? Analysis of opinions from different groups in Brazil. Bioethics. 2003;17:425-31.

16. Guerrine P, Claquin J. Organ and tissue shortage in France. Presse Med. 2006;35:1603-10. 